\title{
Multifactorial Analysis of Affinity-Mass Spectrometry Data from Serum Protein Samples: A Strategy to Distinguish Patients with Preeclampsia from Matching Control Individuals
}

\author{
Ulrich Pecks, ${ }^{\mathrm{a} *}$ Franka Seidenspinner, ${ }^{\mathrm{a}, \mathrm{b} *}$ Claudia Röwer, \\ Toralf Reimer, ${ }^{c}$ Werner Rath, ${ }^{\mathrm{a}}$ and Michael O. Glocker ${ }^{\mathrm{b}}$ \\ ${ }^{a}$ Department of Obstetrics and Gynecology, Medical Faculty, RWTH Aachen, Aachen, Germany \\ b Proteome Center Rostock, Medical Faculty and Natural Science Faculty, University of Rostock, Rostock, Germany \\ ${ }^{\text {c }}$ Department of Obstetrics and Gynecology, Medical Faculty, University of Rostock, Clinic Suedstadt, Rostock, \\ Germany
}

A multifactorial differential analysis of serum proteins using mass spectrometry distinguished samples from pregnant women with severe early-onset preeclampsia $(n=11)$ from those of control individuals with uneventful pregnancies $(n=13)$. Serum proteins were fractionated by either their affinities to reversed-phase material coated magnetic beads or by fractionated precipitation. The on-average most abundant ion signals were observed at $m / z$ 9390, 9103, and 8886. The best differentiating ion signals between the two sample groups were found at $\mathrm{m} / \mathrm{z}$ $13,715,13,834$, and 13,891. The normalized intensities of these ion signals were on-average lower in the preeclampsia group than in the control group. The six ion signal intensities enabled sorting of the individual spectra with high accuracy. Sodium dodecyl sulfate polyacrylamide gel electrophoresis (SDS-PAGE) analysis showed that a protein band migrating just above the $14 \mathrm{kDa}$ marker band contained transthyretin (P02766; $\mathrm{M}_{\mathrm{r}}$ (avg.): 13,761). Densitometric analysis of the transthyretin bands showed lower intensities in the preeclampsia samples with respect to those of the controls. Nephelometric analysis of the serum samples determined the mean concentration of transthyretin in the preeclampsia group were lower $(0.16 \mathrm{mg} / \mathrm{mL}$; range: 0.13 to 0.20 ; SD: 0.03$)$ than that in the control group $(0.19 \mathrm{mg} / \mathrm{mL}$; range: 0.14 to 0.22 ; SD: 0.02 ), substantiating the role of transthyretin concentration differences in the comparison of the two groups. Altogether, our findings support the theory of preeclampsia being a heterogeneous disorder that might be sub-classified by a defined proteome signature in maternal blood using multifactorial analysis of affinity-fractionated serum samples. (J Am Soc Mass Spectrom 2010, 21, 1699-1711) (c) 2010 American Society for Mass Spectrometry

$\mathrm{P}$ reeclampsia is a pregnancy-related hypertensive disorder. It affects $\sim 3 \%$ to $5 \%$ of pregnant women, and is a major cause of maternal and neonatal morbidity and mortality. Because the only definitive treatment available thus far is delivery, preeclampsia is one of the leading causes of a mandated prematurity [1]. Preeclampsia is associated with proteinuria, and its symptoms usually manifest after the 20th week of gestation. It is considered a multisystemic disorder associated with generalized endothelial dys-

Address reprint requests to Dr. M. O. Glocker, Proteome Center Rostock, Department for Proteome Research, Institute of Immunology, Medical Faculty and, Natural Science Faculty, University of Rostock, Schillingallee 69, P.O. Box 100 888, 18055 Rostock, Germany. E-mail: michael.glocker@ med.uni-rostock.de

* These two authors contributed equally to this work. function, thus affecting many organs, including the kidney, liver, and the nervous system [2]. Its major complications are eclampsia and HELLP syndrome, both of which are potential life-threatening events. Eclampsia is characterized by grand mal-like seizures, whereas HELLP syndrome manifests itself with hemolysis, elevated liver enzymes, and low platelet counts [3]. Furthermore, the underlying condition has the potential to affect the fetus, as about $25 \%$ of babies born to women with preeclampsia are small for gestational age (SGA).

The pathogenesis of preeclampsia still remains unclear. Current hypothesis states that placental ischemia is due to a shallow placental trophoblast invasion into the maternal decidua and a lack of spiral artery remodeling $[4,5]$. As a response, the ischemic placenta releases a number of cell fragments and proteins into the maternal circulation. Hence, trophoblast cells and cell- 
free fetal DNA are increased in maternal plasma in pregnancies complicated by preeclampsia [6,7]. Likely the development of preeclampsia involves several different pathophysiological mechanisms, as evidenced by the diversity of proteins that have been studied to date.

The use of a growing number of biomarkers has been suggested for the detection and prediction of preeclampsia. Recently, serum concentrations of proand anti-angiogenic factors, such as placental growth factor (PIGF), soluble vascular endothelial growth factor receptor-1 (sVEGFR-1 or sFlt-1), and soluble endoglin were found to be altered in maternal blood, even weeks before the onset of symptoms [8, 9]. Other molecules that appear promising as early markers include activin A, inhibin A, pentraxin 3 (PTX3), pregnancyassociated plasma protein-A (PAPP-A), and placental protein 13 (PP13) [10-15]. However, a large systematic review in 2004 concluded that no single test currently available to predict preeclampsia was sufficiently reliable for clinical use [16]. Consequently, up to now none of the discussed markers has found widespread application in clinical routine.

One of the approaches to study polygenic diseases that generated considerable interest due to its clinical potential is proteomic pattern diagnostics. Matrixassisted laser desorption/ionization-time of flight mass spectrometry (MALDI-TOF MS) is an automated technique that can detect hundreds of peptide and/or protein ion signals from clinically obtained body fluids in one measurement with good reproducibility and robustness. Hence, MALDI-TOF MS has enabled the multiparametric analysis of the reservoir of proteins derived from high-abundance endogenous circulating molecules from pregnant women [3, 17]. As a consequence, mass spectrometric measurements of the entire set of protein abundances in biological fluids (proteome signatures) allow the representation of a particular pathology, and the resulting signature is in the best case unique to the disease. In everyday application, protein signatures are validated against defined patient cohorts to show their specificities within a particular set of samples. One advantage of proteomics is that this approach does not require prior knowledge of the pathophysiological mechanisms underlying the condition of interest or even the existence of any single specific protein, as long as the signature of recorded signals remains differential [18].

In our study presented here, we aimed as a first step to assess MALDI-TOF mass spectrometry-based serum protein analysis as a means to detect preeclampsia patients by analyzing samples from pregnant women and to investigate the possibility of the method to reliably differentiate patient samples from those of control individuals, a prerequisite for potential clinical use.

\section{Materials and Methods}

\author{
Selection of Patients/Donors, Blood Sample \\ Collection, and Storage of Serum Aliquots
}

The study was approved by the Ethics Committee of the RWTH Aachen (EK 138/06). Written informed consent was obtained from all participating women. We analyzed serum samples from 24 pregnant Caucasian women attending the Department of Obstetrics and Gynecology, University Hospital of the RWTH Aachen between October 2006 and December 2008. Of those, 13 healthy women had an uneventful pregnancy and 11 pregnancies were complicated by preeclampsia.

Preeclampsia was defined by the following criteria: (1) a blood pressure in a previously normotensive woman higher than $140 \mathrm{~mm} \mathrm{Hg}$ systolic or $90 \mathrm{~mm} \mathrm{Hg}$ diastolic on two or more occasions or on automated 24-h blood pressure monitoring, (2) a urinary protein content greater than $300 \mathrm{mg} / \mathrm{L}$ in a 24-h collection, or (3) at least a $2+$ reading in urine dip stick on a random sample. The definition is in accordance to the criteria of the International Society for the Study of Hypertension in Pregnancy and the Consensus Report of the US National High Blood Pressure Education Program [19, 20]. Furthermore, to obtain a homogeneous study group, only patients with early onset preeclampsia $<34+0$ weeks and with appropriate fetal growth were included as already suggested by others [21, 22]. Gestational age was established on the basis of the last menstrual period and confirmed by ultrasonic examination between 10th and 14th week of gestation. Neonatal birth weight centile was determined according to the populationbased newborn weight charts [23]. Patients with clinical or biochemical signs of infection, diabetes, gestational diabetes, or HELLP syndrome at time of sampling were excluded. None of the samples obtained were taken during labor.

Important clinical and laboratory parameters by which the patients and control individuals were characterized were blood pressure, urinary protein content, and week of gestation at time point of sample collection (Table 1). Blood samples (9 mL) were taken antenatally from right or left cubital vein using monovette syringes (Serum Z/9 mL; Monovette, Sarstedt, Germany). After incubation at room temperature for 15-30 min, samples were subjected to sedimentation of blood cells by centrifugation at $2000 \mathrm{~g}$ at room temperature for $15 \mathrm{~min}$. Serum was aspirated and divided into aliquots $(100 \mu \mathrm{L}$ each), which were stored at $-80^{\circ} \mathrm{C}$. Altogether, time between blood sample collection and storage of serum aliquots averaged below $1 \mathrm{~h}$.

\section{Protein Extract Preparation from Serum Samples using the Profiling Kit 100 MB-HIC8}

Serum samples were processed according to manufacturer's instructions using the Profiling Kit 100 MB-HIC8 (Bruker Daltonik, Bremen, Germany). From each thawed 
Table 1. Demographic data and clinical parameters of patients included in the study

\begin{tabular}{|c|c|c|c|c|c|c|c|c|}
\hline $\begin{array}{l}\text { Patient/ } \\
\text { individual }\end{array}$ & $\begin{array}{l}\mathrm{Age}^{\mathrm{a}} \\
{[\mathrm{a}]}\end{array}$ & $\begin{array}{c}\text { BMI before } \\
\text { pregnancy } \\
{\left[\mathrm{kg} / \mathrm{m}^{2}\right]}\end{array}$ & $\begin{array}{l}\text { Gestational } \\
\operatorname{age}^{a}[w+d]\end{array}$ & $\begin{array}{c}\text { Median blood } \\
\text { pressure } \\
{[\mathrm{mm} \mathrm{Hg}]} \\
\end{array}$ & $\begin{array}{l}\text { Proteinuria }^{a, c, d} \\
{[\mathrm{mg} / \mathrm{l}]}\end{array}$ & $\begin{array}{c}\text { Gestational age } \\
\text { at delivery } \\
{[\mathrm{w}+\mathrm{d}]}\end{array}$ & $\begin{array}{c}\text { Birth weight } \\
{[\mathrm{g}]}\end{array}$ & $\begin{array}{l}\text { Birth weight } \\
\text { centile }^{f} \text { [SD] }\end{array}$ \\
\hline 1 & 23 & 29 & $31+6$ & $148 / 101$ & 6760 & $32+0$ & 1325 & -1.52 \\
\hline 2 & 26 & 27 & $27+6$ & $160 / 97$ & 652 & $28+3$ & 830 & -1.43 \\
\hline 3 & 29 & 22 & $32+4$ & $155 / 95$ & $+3^{d}$ & $32+5$ & 1345 & -1.47 \\
\hline 4 & 30 & 37 & $31+5$ & $143 / 84$ & 451 & $31+6$ & 1395 & -0.85 \\
\hline 5 & 24 & 32 & $32+0$ & $153 / 83$ & 9140 & $32+3$ & 1460 & -1.18 \\
\hline 6 & 38 & 19 & $30+4$ & $162 / 97$ & 3382 & $31+1$ & 1730 & 0.10 \\
\hline 7 & 32 & 26 & $29+2$ & $142 / 84$ & 555 & $32+2$ & 1465 & -1.17 \\
\hline 8 & 26 & 21 & $32+4$ & $145 / 88$ & 2293 & $33+1$ & 1690 & -1.22 \\
\hline 9 & 46 & 23 & $25+4$ & $183 / 105$ & 2342 & $26+2$ & 760 & -1.00 \\
\hline 10 & 33 & 23 & $23+6$ & $144 / 93$ & 384 & $25+5$ & 680 & -1.02 \\
\hline 11 & 34 & 23 & $32+0$ & $176 / 113$ & 2684 & $32+2$ & 1380 & -1.38 \\
\hline 12 & 31 & 37 & $30+4$ & $122 / 74$ & 180 & $38+5$ & 2800 & -1.33 \\
\hline 13 & 28 & 40 & $33+6$ & $128 / 74$ & 96 & $39+0$ & 3850 & 0.86 \\
\hline 14 & 21 & 19 & $31+5$ & $111 / 65$ & 49 & $39+0$ & 3700 & 0.50 \\
\hline 15 & 33 & 28 & $30+3$ & $111 / 65$ & 79 & $38+6$ & 3710 & 0.85 \\
\hline 16 & 38 & 21 & $28+0$ & $98 / 52$ & $+1^{d}$ & $38+0$ & 3340 & -0.04 \\
\hline 17 & 28 & 21 & $24+0$ & $95 / 60$ & $0^{d}$ & $41+0$ & 3995 & 0.81 \\
\hline 18 & 30 & 33 & $28+3$ & $111 / 56$ & $0^{d}$ & $36+1$ & 2630 & -0.80 \\
\hline 19 & 26 & 20 & $28+2$ & $130 / 70$ & $0^{d}$ & $37+6$ & 2915 & -0.65 \\
\hline 20 & 39 & 22 & $28+0$ & $120 / 70$ & $0^{d}$ & $37+3$ & 2860 & -0.78 \\
\hline 21 & 40 & 26 & $32+2$ & $120 / 75$ & $0^{d}$ & $38+2$ & 2590 & -1.83 \\
\hline 22 & 28 & 30 & $31+3$ & $134 / 72$ & $0^{d}$ & $38+4$ & 3335 & -0.05 \\
\hline 23 & 27 & 23 & $30+5$ & $120 / 46$ & $0^{d}$ & $41+4$ & 3485 & -0.34 \\
\hline 24 & 35 & 19 & $30+0$ & $103 / 60$ & $0^{d}$ & $38+6$ & 3120 & -0.56 \\
\hline
\end{tabular}

${ }^{a}$ At beginning of hospitalization (time point of sample collection).

bystolic/diastolic blood pressure; preeclampsia is defined as $>140 \mathrm{~mm} \mathrm{Hg}$ systolic or $>90 \mathrm{~mm}$ Hg diastolic blood pressure in women who were normotensive prior to the 20th week of gestation.

'Immunoturbidimetric assay (Tina-quant albumin; Roche Diagnostics, Mannheim, Germany); proteinuria is defined as urinary protein excretion $>300 \mathrm{mg} / \mathrm{L}$.

${ }^{\mathrm{d} D i p}$ stick assay; significant proteinuria is present with readings of more than +1 .

e Gestational weeks at time point of delivery.

fStandard deviations to the mean birth weight centiles according to the population based newborn weight charts.

serum sample, $5 \mu \mathrm{L}$ were incubated with $10 \mu \mathrm{L}$ MBHIC8 "binding buffer" and $5 \mu \mathrm{L}$ of MB-HIC8 bead slurry for $1 \mathrm{~min}$. After washing twice $(100 \mu \mathrm{L}$ of "wash buffer," each), proteins were eluted with $10 \mu \mathrm{L}$ of "elution buffer," consisting of a 50\% ACN solution.

\section{Protein Extract Preparation from Serum Samples by Fractionated Precipitation}

Serum samples were thawed and fractionated precipitation was performed according to described procedures [24]. Briefly, to $10 \mu \mathrm{L}$ of serum sample, $7 \mu \mathrm{L}$ of chilled ethanol $\left(-20^{\circ} \mathrm{C} ; 40 \%\right.$ ethanol, vol/vol $)$ was added and kept on ice for $10 \mathrm{~min}$. The pellet (fraction I) was collected by centrifugation with $13,000 \mathrm{~g}$ at $4{ }^{\circ} \mathrm{C}$. Proteins dissolved in the ice-cold supernatant $(17 \mu \mathrm{L})$ were precipitated by addition of $3 \mu \mathrm{l}$ of chilled ethanol (50\% ethanol, vol/vol). After $10 \mathrm{~min}$ incubation at $-20^{\circ} \mathrm{C}$, precipitated proteins (fraction II) were collected by centrifugation as described above.

\section{MALDI-TOF MS Profiling of Serum Proteins}

After MB-HIC8 extraction, protein solutions $(0.5 \mu \mathrm{L}$ each) were spotted directly onto a stainless steel MTP
384 target plate (Bruker Daltonik) before matrix solution was added (see below). Alternatively, after fractionated precipitation protein pellets were re-dissolved in $10 \mu \mathrm{L}$ of a solution consisting of $50 \% \mathrm{ACN} / 0.3 \%$ TFA $/ 5 \mathrm{mM} n$-OGP and agitated for $30 \mathrm{~min}$. Insoluble remainders were disposed by centrifugation before further use of the solubilized sample; $0.5 \mu \mathrm{L}$ from the protein solution were deposited on a stainless steel MTP 384 target plate. In either case $1.5 \mu \mathrm{L}$ of saturated ferulic acid solution (dissolved in $\mathrm{ACN} / 0.1 \%$ aqueous TFA $(33 / 67, \mathrm{vol} / \mathrm{vol}))$ was added as matrix to each sample spot. For each sample, spots were prepared in duplicate for recording first and second measurements, M1 and M2, respectively. The entire profiling procedure was repeated and all samples were examined once again in duplicate, yielding in measurements M3 and M4. One sample measurement series (M5) was recorded after fractionated precipitation. Protein mixtures were analyzed with a Reflex III MALDI TOF mass spectrometer (Bruker Daltonik) equipped with the SCOUT source and delayed extraction and operated in linear positive ion mode using an acceleration voltage of 20 $\mathrm{kV}$ [25]. Spectra were recorded in a mass range from 4 to $25 \mathrm{kDa}$ and 20 to $250 \mathrm{kDa}$, respectively, accumulating 900 shots per spectrum. Spectra were externally calibrated 
using a commercially available Protein Calibration Standard (Bruker Daltonik).

\section{Bioinformatic Analysis of Linear MALDI-TOF MS Ion Signals}

The ClinProTools 2.2 software (Bruker Daltonik) was used to analyze the spectra from the patients and controls, respectively. Each dataset was generated in duplicate, i.e., two independent measurements were recorded from each sample. The first sample work-up with the beads resulted in datasets $\mathrm{M} 1$ and M2, and the second work-up in datasets M3 and M4, respectively. The work-up with fractionated precipitation yielded in dataset M5. Analysis for each dataset was carried out independently from each other. Settings were specified and remained unchanged for all measurement analyses for (1) peak picking, which happened on the total average spectrum of the particular class, (2) for signal to noise threshold, value was set to 5.00, and (3) the value for the relative threshold base peak was set to 0.00 . Smoothing of spectra was performed applying the Savitzky-Golay algorithm, width $2.0 \mathrm{~m} / \mathrm{z}$ for three cycles. Spectra were recalibrated automatically, taking only those masses into account that occurred in at least $30 \%$ of the spectra. The maximal mass tolerance between reference mass and peak mass was set to 1500 ppm. Hence, those spectra were excluded from analysis which either could not be recalibrated due to larger mass differences or which contained too few ion signals for calibration. Baseline subtraction was performed in the "Top Hat Baseline mode" and null spectra exclusion was enabled. All ion intensities in the spectra were normalized to their own total ion count (TIC), which was determined as the sum of all intensities of the spectrum. Subsequently, all intensities of this spectrum were divided by the obtained TIC value. Statistical significance of the mass spectra was analyzed with a Wilcoxon rank-sum test [26] expanded by the use of a Kruskal-Wallis test [27] and a Student's t-test for two populations $[28,29]$ expanded by the use of an ANOVA test on significance levels of 0.05 . Probability distributions were analyzed with an Anderson-Darling test [30]. The Wilcoxon rank-sum test is a nonparametric significance test for assessing two samples from a single population, whereas the Kruskal-Wallis test is applied instead of the Wilcoxon rank-sum test when more than two populations are involved. In our studies, the statistical analyses of the mass spectra were performed with a Wilcoxon rank-sum test. The two-sided two-sample Student's t-test that was applied in our studies is used for comparing two populations and their data differences. The ANOVA test can be applied instead of the Student's $t$-test when more than two populations are involved. The Wilcoxon rank-sum test, in contrast to the Student's $t$-test, does not assume normally distributed data. Statistical significance between ion signal quotients among the two groups was tested with a two-sided Student's $t$-test for two populations on a significance level of 0.05 . Graphical representations as box-and-whisker plots [31] were realized using the Origin software (version 6.1G; OriginLab Corporation, Northampton, MA, USA).

\section{SDS Polyacrylamide Electrophoresis and Gel Imaging}

Proteins from the pellet of fraction II were re-dissolved in $300 \mu \mathrm{L}$ of SDS sample buffer (2\% SDS, $65 \mathrm{mM}$ Tris $/ \mathrm{HCl}$ ( $\mathrm{pH}$ 6.8), 5\% glycerol, and bromophenol blue) at room temperature. SDS PAGE was carried out as described [32]. In short, SDS polyacrylamide gels, $10 \% \mathrm{~T}$ for the analysis of high mass proteins and $12 \% \mathrm{~T}$ for analyzing proteins in the low mass range (Invitrogen, Carlsbad, CA, USA), were run for $1 \mathrm{~h}$ at $200 \mathrm{~V}$ in a Novex Minicell Vertical Electrophoresis System (Invitrogen) applying the Laemmli continuous buffer system [33]. Gels were fixed and then stained with colloidal Coomassie brilliant blue G-250 [34, 35]. The broad range marker kit (New England BioLabs Inc., Frankfurt am Main, Germany) was used as apparent molecular mass calibration. Stained gels were scanned with the Umax Mirage II Scanner (Umax Data Systems, Willich, Germany) and images were stored as 16 bit tif files. For densitometric image analysis the software package Phoretix 2D Advanced, version 6.01 (Nonlinear Dynamics Ltd., Newcastle upon Tyne, UK) was used.

\section{Mass Spectrometric Peptide Mass Fingerprinting}

Protein bands of interest were excised manually and gel plugs were subjected to in-gel digestion with trypsin (Promega, Mannheim, Germany) [3]. Sample preparation of peptide mixtures was performed on an AnchorChip 600/384 target plate [32] using CHCA as matrix. Peptide mixtures were analyzed with a Reflex III MALDI TOF mass spectrometer (Bruker Daltonik) equipped with the SCOUT source and delayed extraction and operated in positive ion mode using an acceleration voltage of $20 \mathrm{kV}$ [25]. Spectra were externally calibrated using a commercially available Peptide Calibration Standard (Bruker Daltonik) as well as internally recalibrated using the following peptide ion signals derived from trypsin autoproteolysis: $[\mathrm{M}+\mathrm{H}]^{+}$ 842.51, $[\mathrm{M}+\mathrm{H}]^{+}$1045.54, $[\mathrm{M}+\mathrm{H}]^{+}$2211.10, $[\mathrm{M}+\mathrm{H}]^{+}$ 2807.39. Mass spectra were further processed and analyzed with the FlexAnalysis 2.4 and BioTools 3.0 softwares (both Bruker Daltonik). Database searches were performed against an in-house SWALL database that consists of Swiss-Prot release 56.8 and TrEMBL release 39.8 using Mascot version 2.2.03 software (Matrix Science, London, UK) with the following search parameters: taxonomy: human, peptide tolerance: 60 ppm, fixed modifications: carbamidomethylation of cysteines, variable modifications: oxidation of methionines, 1 missed cleavage site. 


\section{Mass Spectrometric Peptide Sequencing}

Peptide mixtures from in-gel digests $(1 \mu \mathrm{L})$ were mixed with matrix solution ( $1 \mu \mathrm{L}$ ) on an AnchorChip 600/384 target plate. The matrix solution contained $5 \mathrm{mg}$ DHB which were dissolved in $1 \mathrm{~mL}$ of solvent that consisted of $50 \% \mathrm{ACN}$ and $50 \%$ of a $0.1 \%$ TFA solution ( $\mathrm{vol} / \mathrm{vol}$ ). MS/MS spectra were recorded on an Axima MALDI QIT TOF mass spectrometer (Shimadzu Biotech, Manchester, UK) utilizing a nitrogen pulsed laser (337 nm, 3-5 ns pulse length) and employing a three-dimensional ion trap supplied by helium (pulsed flow gas) for collisional cooling and argon (collisional gas) for collisionally induced dissociation (CID) $[36,37]$. Precursor ions were excited with off-resonance sinusoidal waveforms whereas at the same time argon was allowed to enter the trap. For fragmentation, the width of the precursor ion selection window was dependent on the mass of the precursor ion and varied between 2 and 10 Da. Spectra were externally calibrated with a manually mixed peptide standard consisting of bradykinin (1-7), $[\mathrm{M}+\mathrm{H}]^{+}$ 757.39; angiotensin II, [M $+\mathrm{H}]^{+}$1046.53; angiotensin I, $[\mathrm{M}+\mathrm{H}]^{+}$1296.68; bombesin, $[\mathrm{M}+\mathrm{H}]^{+} 1619.81 ; \mathrm{N}-$ acetyl renin substrate, $[\mathrm{M}+\mathrm{H}]^{+}$1800.93; ACTH (1-7), $[\mathrm{M}+\mathrm{H}]^{+}$2093.08; ACTH (18-39), $[\mathrm{M}+\mathrm{H}]^{+}$2465.19; somatostatin, $[\mathrm{M}+\mathrm{H}]^{+}$3147.46; insulin (oxidized beta chain), $[\mathrm{M}+\mathrm{H}]^{+}$3494.64; as well as internally recalibrated using known ion signals of the MS/MS spectrum. Further processing and analysis of the MS/MS spectra was performed with the Launchpad software, version 2.8.4 (Shimadzu Biotech, Manchester, UK).

\section{Nephelometric Determination of Transthyretin Levels in Serum}

Concentrations of transthyretin in serum samples were determined nephelometrically using the Dade Behring assay system at the automated Dade Behring Nephelometer II (BN II; Dade Behring, Marburg, Germany) according to the manufacturer's protocol. Reference values for transthyretin in serum are $0.2-0.4 \mathrm{mg} / \mathrm{mL}$ according to the method sheet; $250 \mu \mathrm{L}$ of freshly thawed serum was used for each measurement.

\section{Statistical Power Analysis}

To evaluate the minimal required sample size that is needed to discriminate the group with preeclampsia from the control group on the basis of the obtained data, we carried out a power analysis [38, 39] using the MedCalc statistical software. We chose a type I error $(\alpha)$ of 0.05 and a type II error $(\beta)$ of 0.20 in a comparison of two means which is typically suggested for this type of analysis. Thus, we achieved a minimal required sample size with a power $(1-\beta)$ of $80 \%$ and a level of significance below 0.05 .

\section{Results}

\section{Selection of Patients and Sample Preparations}

Patient samples were selected such as to attain a homogenous study group by focusing on the more severe early-onset form ( $<34$ gestational week) of preeclampsia. The late-onset form is more evanescent and of lesser clinical importance [40]. Furthermore, we excluded women with concomitant intrauterine growth restriction (as defined by a decrease in growth velocity) or small-for-gestational-age neonates (SGA, as defined by a birth weight centile below -2 SD of the mean). Twenty-four pregnant women at median age of $30 \mathrm{y}$ (range: 21-45 y) were included in the study. The patient group comprised 11 pregnant women with early onset preeclampsia (PE). The control group consisted of 13 healthy pregnant women with uneventful pregnancies (CN) matching with the PE group in both maternal and gestational age (Table 1). All women in the PE group required iatrogenic preterm delivery before 34 completed weeks of gestation because of deteriorating maternal condition and/or signs of fetal distress. Hence, despite the set exclusion criteria, birth weight centiles were significantly reduced in our study group compared with the healthy control group.

From all individuals, blood samples were taken and serum proteins were isolated with standardized procedures. Subsequently, fractionation of serum proteins was conducted by either applying a reversed-phase coated bead system (ClinProt) or by conducting fractionated precipitation. Both approaches proved equally suitable for fractionation of serum proteins and yielded in samples that were applicable for MALDI-MS profiling without further work-up (see below). An overview mass spectrum in the "high mass" range showed protein ion signals between $m / z$ 25,000 and 200,000 (Figure $1)$. The on-average most prominent ion signals were found at $m / z 66,447,33,282$, and 28,050. These were assigned as the singly and doubly charged ion signals of human serum albumin ( $\mathrm{M}_{\mathrm{r}}$ (avg.): 66,437) and the singly charged ion signal of apolipoprotein A-I $\left(\mathrm{M}_{\mathrm{r}}\right.$ (avg): 28,079), respectively.

The mass spectrometric result matched well with SDS PAGE analysis of the fractionated samples (insert in Figure 1, lane 2) where protein bands were observed between 25 and $220 \mathrm{kDa}$ apparent molecular mass. Comparison of the gel band pattern before (insert in Figure 1, lane 1) and after fractionation showed that fractionation removed most of the very high mass proteins (above $220 \mathrm{kDa}$ ) and seemed to enrich for some proteins in the mass range between $150 \mathrm{kDa}$ and $97 \mathrm{kDa}$ apparent molecular mass. Note that the strong band at apparent molecular mass of $55 \mathrm{kDa}$ was identified as human serum albumin (P02768; $\mathrm{M}_{\mathrm{r}}$ (avg.): 66,437) and the band migrating at $26 \mathrm{kDa}$ apparent mass was identified as apolipoprotein A-I (P02647; $\mathrm{M}_{\mathrm{r}}$ (avg.): $28,079)$ by in-gel tryptic digest and peptide mass fingerprinting (data not shown). 


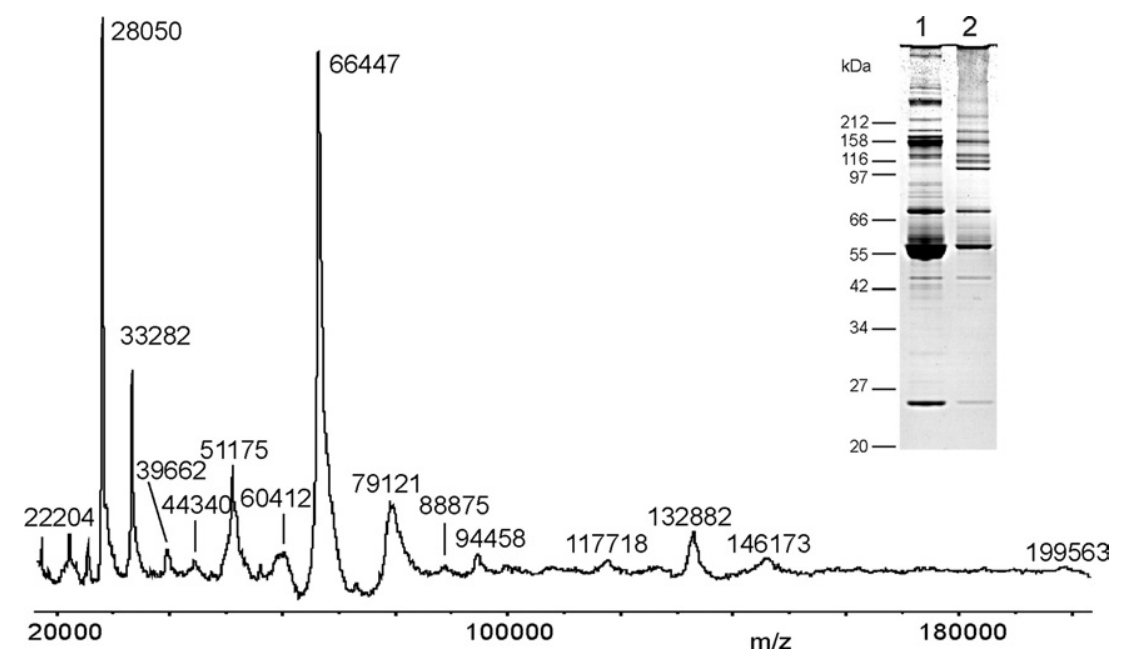

Figure 1. Overview of protein ion signals recorded by MALDI-TOF-MS analysis after fractionated precipitation from a serum sample of a patient with preeclampsia (mass range $m / z 20,000-220,000$; selected ion signals are labeled). Ion signals were observed up to ca. $200 \mathrm{kDa}$. Ferulic acid was used as matrix. The insert shows the SDS-PAGE analysis (10\% T, Coomassie blue staining) of a serum sample before (lane 1) and after fractionated precipitation (lane 2). After fractionated precipitation protein bands were detected below $220 \mathrm{kDa}$. The locations of marker proteins with known apparent masses are indicated to the left.

Protein ion signals in the mass range above $\mathrm{m} / \mathrm{z}$ 70,000 appeared small in the linear TOF MALDI mass spectra, presumably due to the rather poor sensitivity of the multichannel plate detector for high mass ions. Analysis of the ion signal intensities above $\mathrm{m} / \mathrm{z} 20,000$ showed that there were no significant differences between the spectra of the two sample groups. Hence, further analysis was focused on the "low mass" range, i.e., between $\mathrm{m} / \mathrm{z} 4000$ and 25,000 . As a first measure- ment series, we used the samples after work-up with the Profiling Kit 100 MB-HIC8 that makes use of reverse-phase material coated on magnetic beads. Afterwards, on-average 30 intense ion signals were detected in a reproducible manner (Figure 2).

It is of note that in the linear MALDI-TOF mass spectra well resolved ion signals were observed in the mass range below $m / z$ 20,000, whereas in SDS PAGE analyses of the same samples there were only faintly

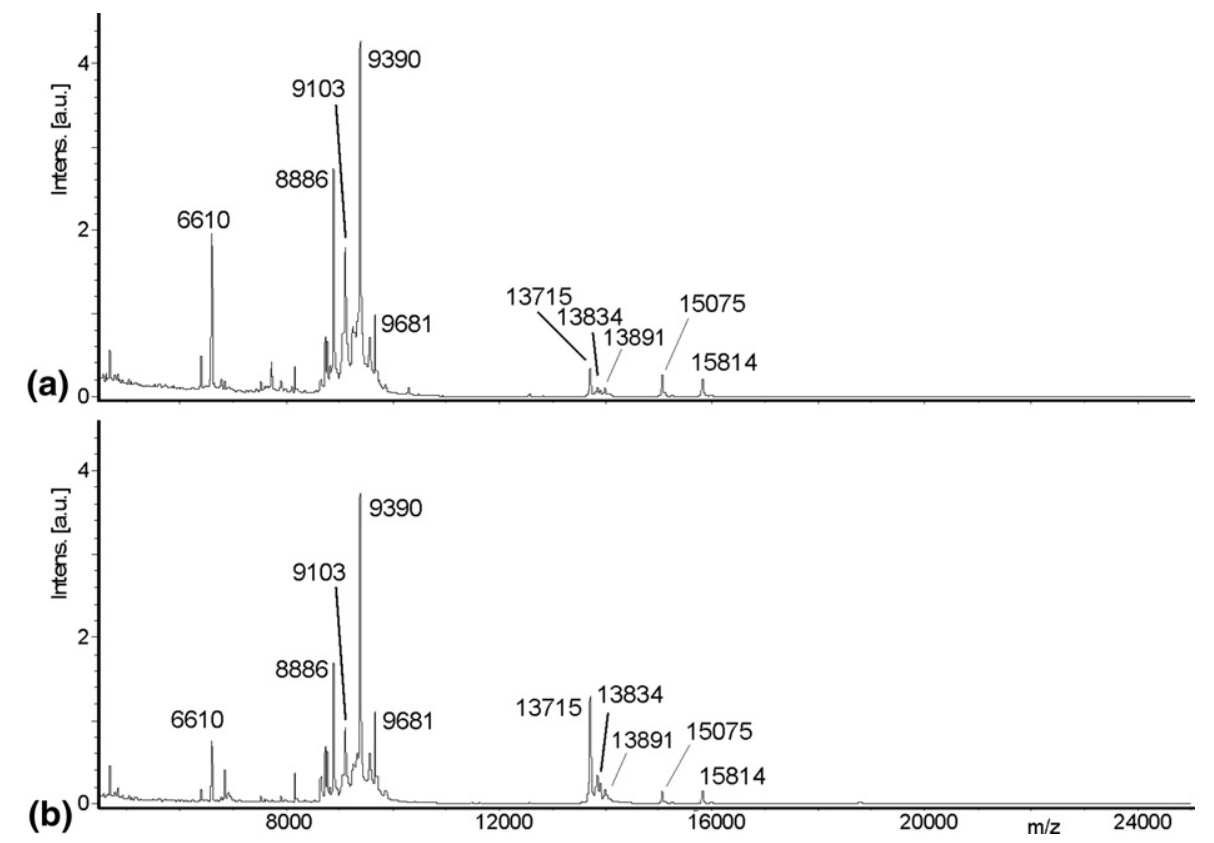

Figure 2. MALDI-TOF mass spectra of serum samples after ClinProt work-up. (a) Sample from a preeclampsia patient. (b) Sample from a control individual. Mass range $m / z$ 4500-25,000; selected ion signals are labeled; ferulic acid was used as matrix. 
staining bands detected below $20 \mathrm{kDa}$ apparent mass when using $10 \%$ gels. This finding may be attributed to the generally poorer staining properties of smaller proteins compared with larger proteins and to migration properties in this mass range so that proteins are not well focused into sharp bands.

\section{Mass Spectrometric Profiling of Fractionated Serum Samples from Patients and Control Individuals using the ClinProt Work-Up Procedure}

MALDI linear TOF mass spectra from patient and control samples in general looked very similar to each other making a semi-quantitative analysis of the ion signal intensities feasible. The on-average most abundant ion signals in this mass range were observed at $\mathrm{m} / \mathrm{z}$ 9390, 9103, and 8886 (Table 2) in all spectra.

To decide whether a distinct ion signal group could be considered as significantly different in abundance between the preeclampsia group and the control group, we performed statistical analyses of the mass spectra using the ClinProTool software package. According to the calculated $P$ values, the best differentiating singly charged ion signals between the two sample groups were found at $m / z 13,715,13,834$, and 13,891 together with their doubly charged ion signals (Table 2). However, separation of the two groups based on one of these ion signal differences alone was not satisfactory as abundance differences within one group varied too much (Figure 3). Nevertheless, there was a noticeable trend of the ion signal abundances around $m / z$ 13,715 being less intense in the preeclampsia group compared with the control group.

To better distinguish between the two groups and to more accurately assign a given spectrum to either belonging to the preeclampsia or the control group, a multiparametric analysis was performed in which the normalized ion signal areas (Supplemental Table 1, which can be found in the electronic version of this article) within each spectrum were brought into context to each other.

It turned out that the three most intense singly charged ion signals and the three best differentiating

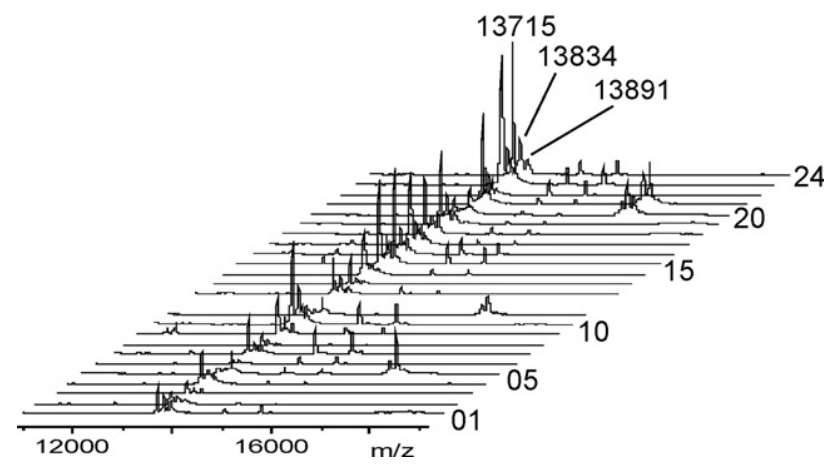

Figure 3. Zoom view of protein ion signals in serum samples after fractionated precipitation by MALDI-TOF-MS; mass range $m / z$ 13,000-15,000. Spectra from individual samples are visualized in staggered mode. Numbering of spectra resembles that of patient samples (cf. Table 1).

singly charged ion signals carried enough information to form rules by which the relations of the ion signal intensities enabled accurate sorting of individual spectra, i.e., of individual samples.

\section{Statistical Analysis of Preeclampsia Versus Control Samples after ClinProt Work-Up}

The first measurement series (MS1) that was recorded after ClinProt work-up was chosen as the training set for developing the method. The simplest rules that we selected were to relate the selected ion signals pairwise. Quotients of the areas of the ion signals at (1) $m / z 13,715$ and 13,834, (2) $m / z 13,891$ and 8886, (3) $m / z 13,751$ and $8886,(4) \mathrm{m} / \mathrm{z} 13,715$ and 9103 , as well as (5) $\mathrm{m} / \mathrm{z} 13,834$ and 9390 were formed. The resulting ratio distributions were determined for each of the five pairs (Figure 4) and showed in fact significant differences $(P$ values below 0.05 ) of the value distributions in all five cases.

Consequently, cut-off values (dashed lines in Figure 4) could be determined for all five ratios such that they were located between the upper $75 \%$ quartile of the group where lower values were obtained (preeclampsia group) and below the $25 \%$ quartile of the other group (control) where on-average higher values were calculated for the respective ratios of ion signal areas.

Table 2. Statistical data of ion signals selected for multiparametric analysis

\begin{tabular}{crllllc}
\hline Entry & $m / z$ & Charge & PTTA & PWKW & PAD & Peak area/std dev $^{\mathrm{a}}$ Rank $^{\mathrm{b}, \mathrm{c}}$ \\
\hline \hline 1 & 13891 & $1+$ & 0.019 & 0.000415 & 0.0273 & $70.57 / 29.16$ \\
2 & 6945 & $2+$ & 0.12 & 0.17 & 0.00524 & $15.81 / 6.27$ \\
3 & 13834 & $1+$ & 0.0496 & 0.0114 & 0.00843 & $121.17 / 49.68$ \\
4 & 6917 & $2+$ & 0.0496 & 0.0114 & 0.0912 & $38.01 / 11.77$ \\
5 & 13715 & $1+$ & 0.0383 & 0.00536 & 0.00167 & $280.93 / 136.72$ \\
6 & 6858 & $2+$ & 0.037 & 0.00288 & 0.00142 & $77.24 / 25.47$ \\
7 & 9390 & $1+$ & 0.885 & 1 & 0.174 & $3109.2 / 899.53$ \\
8 & 9103 & $1+$ & 0.65 & 0.621 & 0.265 & $1660.76 / 458.3$ \\
9 & 8886 & $1+$ & 0.298 & 0.203 & 0.345 & $1803.66 / 452.78$ \\
\hline
\end{tabular}

a Values from measurement series MS1 of the preeclampsia group.

bEntries 1-6: best differentiating ion signals according to peak statistics (PTTA $=P$ value from combined paired Student's $t$-test and ANOVA test; PWKW $=P$ value from combined Wilcoxon rank-sum test and Kruskal-Wallis test; PAD $=P$ value from Anderson-Darling test).

'Entries 7-9: most intense ion signals according to average peak areas. 
(a)

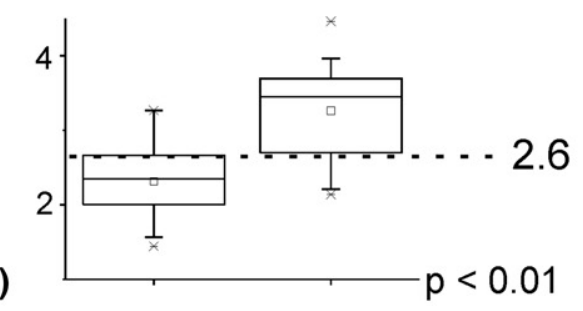

(b)

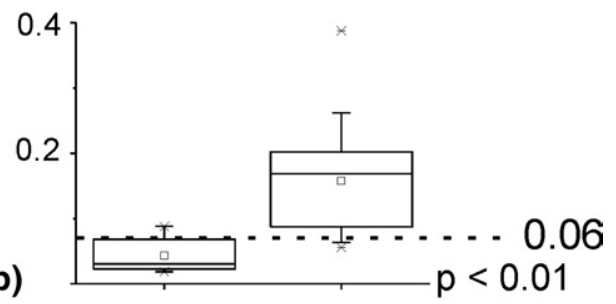

(c)

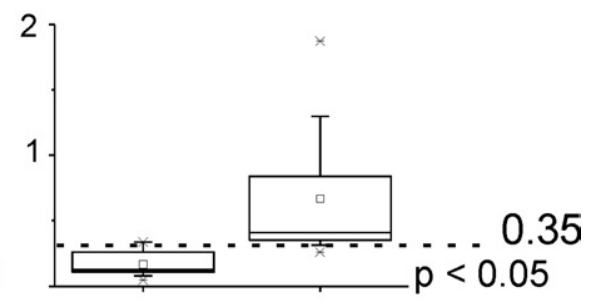

(d)
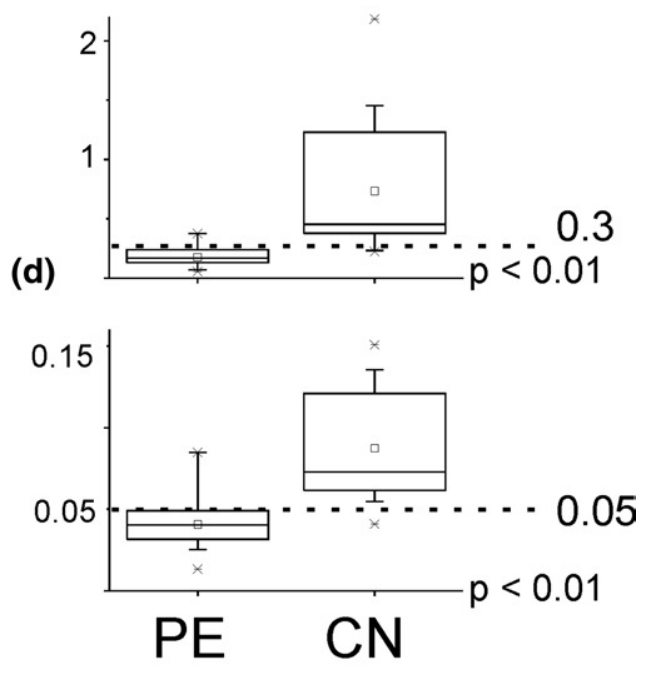

(e) $\quad(n=11) \quad(n=13)$

Figure 4. Box and whisker plots for selected ion intensity differences from measurement one after ClinProt work-up of serum samples. (a) Distribution of signal area values of quotient for $\mathrm{m} / \mathrm{z}$ 13,715 and 13,834. (b) Distribution of signal area values of quotient for $m / z 13,891$ and 8886. (c) Distribution of signal area values of quotient for $\mathrm{m} / \mathrm{z} 13,715$ and 8886. (d) Distribution of signal area values of quotient for $\mathrm{m} / \mathrm{z} 13,715$ and 9103. (e) Distribution of signal area values of quotient for $\mathrm{m} / \mathrm{z} 13,834$ and 9390 . The boxes represent the 25th-75th percentiles. The horizontal lines within the boxes represent the median, the small squares indicate the mean. The whiskers specify the 5th and 95th percentiles, and the crosses indicate the 1st and 99th percentiles. Dashed lines mark selected cut-off values. PE: preeclampsia; $\mathrm{CN}$ : control. $P$ values are given.

Next, it was tested whether in a given sample spectrum the respective cut-off value was reached or not. When the value of one quotient was higher than the respective cut-off, a score of " 1 " was given to this respective sample. In the contrary case, the score for this sample was set to "0." This check was carried out for each of the five ion signal ratios independently. Hence, each spectrum, i.e., each sample, could ultimately reach a cumulative score between " 0 " and " 5 ." Subsequently, it was determined that a cumulative score above " 2 " was sorting the respective spectrum (sample) into the preeclampsia group. Applying these grouping rules for the values of the first measurement series (M1) enabled a clear-cut separation of all preeclampsia samples into the preeclampsia group and all control samples into the control group (Table 3). Ultimately, the scoring system resulted in a sensitivity of 1.00 , a specificity of 1.00 , a false positive rate of 0.00 , a false negative rate of 0.00 , a positive predictive value of 1.00 , and a negative predictive value of 1.00 for the first measurement series (MS1).

Now we applied the very same rules to the second measurement series (MS2) using the normalized ion signal areas from this measurement (Supplemental Table 2). This measurement series was recorded a few days later than the first measurement series (MS1) without fresh fractionation work-up. Hence, this measurement series can be regarded as a first test case. A decrease in the accuracy of the separation procedure was expected. However, the decrease in specificity to 0.62 and a false positive rate of 0.38 was regarded as being too large to qualify our approach as a satisfactory procedure. To determine whether the poor statistical significance obtained with the second measurement series (MS2) was due to non-satisfactory separation rules or to sample deterioration during storage after work-up, we performed a new fractionation experiment with freshly thawed aliquots from the clinical samples, following the exact same work-up protocol as before.

A third measurement series (MS3; Supplemental Table 3) was recorded and analyzed again directly after work-up. The over-all analysis results showed that now a sensitivity of 0.91 , a specificity of 0.85 , a false positive rate of 0.15 , a false negative rate of 0.09 , a positive predictive value of 0.83 , and a negative predictive value of 0.92 was reached with this measurement series. To confirm that after work-up the samples deteriorated over time, a fourth measurement series (MS4; Supplemental Table 4) was recorded again a few days later with the material from the second fractionation. As expected, the specificity dropped to 0.69 yielding in a false positive rate of 0.31 .

\section{Verification of the Differentiation Results by Using Fractionated Precipitation as Work-Up}

Next, we checked whether the ion signal differences recorded in the measurement series MS1 to MS4 were merely a result of the work-up procedure using reversed-phase material coated magnetic beads. To do this, we were working-up the starting material, i.e., frozen patient serum samples, by applying a fractionated precipitation procedure. Fraction II from this pro- 
Table 3. Statistical significance of mass spectrometric profiling results

\begin{tabular}{|c|c|c|c|c|c|c|c|c|c|c|}
\hline Measurement & $\begin{array}{c}\text { True } \\
\text { positive }\end{array}$ & $\begin{array}{c}\text { False } \\
\text { positive }\end{array}$ & $\begin{array}{c}\text { True } \\
\text { negative }\end{array}$ & $\begin{array}{c}\text { False } \\
\text { negative }\end{array}$ & Sensitivity & Specificity & $\begin{array}{c}\text { False } \\
\text { pos. } \\
\text { rate }\end{array}$ & $\begin{array}{c}\text { False } \\
\text { neg. } \\
\text { rate }\end{array}$ & $\begin{array}{l}\text { Pos. } \\
\text { pred. } \\
\text { value }\end{array}$ & $\begin{array}{l}\text { Neg. } \\
\text { pred. } \\
\text { value }\end{array}$ \\
\hline $\mathrm{MS}^{\mathrm{a}}$ & 11 & 0 & 13 & 0 & 1.00 & 1.00 & 0.00 & 0.00 & 1.00 & 1.00 \\
\hline $\mathrm{MS2}^{\mathrm{a}}$ & 10 & 5 & 8 & 1 & 0.91 & 0.62 & 0.38 & 0.09 & 0.67 & 0.89 \\
\hline $\mathrm{MS}^{\mathrm{b}}$ & 10 & 2 & 11 & 1 & 0.91 & 0.85 & 0.15 & 0.09 & 0.83 & 0.92 \\
\hline $\mathrm{MS}^{\mathrm{b}, \mathrm{c}}$ & 10 & 4 & 9 & 0 & 0.91 & 0.69 & 0.31 & 0.09 & 0.71 & 0.90 \\
\hline $\mathrm{MS5}^{\mathrm{d}}$ & 10 & 1 & 12 & 1 & 0.91 & 0.92 & 0.08 & 0.09 & 0.91 & 0.92 \\
\hline
\end{tabular}

${ }^{\text {a } F i r s t ~ C l i n P r o t ~ w o r k-u p . ~}$

becond ClinProt work-up.

"spectra from patients $12,14,21$, and 23 were of poor quality; samples were set to "false positive."

dFractionated precipitation work-up.

cedure was subjected to immediate linear MALDI TOF mass spectrometric analysis (measurement series MS5). Obviously, as the protein mixtures in these samples were different from those obtained with the ClinProt work-up protocol, the spectra of measurement series MS5 looked slightly different than those obtained e.g., from measurement series MS1. Yet, the spectra that were obtained for all 24 samples from this work-up again showed that the most intense ion signals were the same as those obtained after ClinProt work-up. The only significant difference between the spectra was the relative ion signal intensities and the respective ion signal areas (Supplemental Table 5) so that different values resulted for their quotients.

Nevertheless, it was again possible to assign cut-off values using the same procedure as described above (Figure 5) and only in the case of the ratio of the pair with $m / z 13,834$ and 9390, the chosen cut-off value was above the lower $25 \%$ quartile of the control group (Scheme E in Figure 5).

Despite this fact, we decided to not change the rules and scored the spectra, i.e., samples, exactly as described above using the cut-off values from measurement series MS5. As a result, we obtained comparably cumulative scores and sorting of each sample resulted in a sensitivity of 0.91 , a specificity of 0.92 , a false positive rate of 0.08 , a false negative rate of 0.09 , a positive predictive value of 0.91 , and a negative predictive value of 0.92 (Table 3), which was considered quite satisfactory.

\section{SDS Polyacrylamide Gel Analysis of Preeclampsia and Control Samples}

As two completely independent protein fractionation procedures enabled the differentiation of the preeclampsia group from the control group by analyzing the linear MALDI TOF mass spectra with high accuracy, we analyzed selected patient and control samples, i.e., fraction II after fractionated precipitation, also by SDS PAGE. Special interest was given to the mass range below $20 \mathrm{kDa}$ apparent mass, and therefore a 12\% gel was used. Protein bands were visualized by colloidal Coomassie brilliant blue staining (Figure 6).

About six protein bands were visible in the mass range between 20 and $6.5 \mathrm{kDa}$ in both, the preeclampsia samples (patients 5 and 7) and the control individuals (15 and 23) before (lanes 1) and after (lanes 2) fractionated precipitation. The four intense protein bands were subjected to mass spectrometric identifications after in-gel digestion with trypsin. From these analyses, it was found that the band migrating at $20 \mathrm{kDa}$ apparent mass contained the retinol binding protein 4 (P02753; $\mathrm{M}_{\mathrm{r}}$ (avg.): $20,943)$ as the major compound. The band migrating below was determined to contain apolipoprotein A-II (P02652; $\mathrm{M}_{\mathrm{r}}$ (avg.): 17,160 for the homodimer). The band migrating just above the $14 \mathrm{kDa}$ marker band contained transthyretin (P02766; $\mathrm{M}_{\mathrm{r}}$ (avg.): 13,761) and the band at $6.5 \mathrm{kDa}$ apparent mass contained apolipoprotein C-III (P02656; $\mathrm{M}_{\mathrm{r}}$ (avg.): 8765). All identifications were obtained with good identification scores (data not shown), indicating that the identified proteins were in fact the major compounds in their respective bands.

Densitometric analysis of the protein bands of the SDS PAGE analysis showed that the intensities of the bands that contained transthyretin were lower in the preeclampsia samples with respect to those of the control samples. For normalization, the band intensities were set into relation to the intensities of the apolipoprotein A-I bands of the very same sample (band migrating at $26 \mathrm{kDa}$ apparent mass, cf. Figure 1). Such normalized transthyretin band volumes were determined using the serum samples before fractionation (lanes 1 in Figure 6) and yielded in values of 0.057 (patient 5) and 0.089 (patient 7) for the preeclampsia group. The respective values of the samples from the control group were 0.137 (control 23) and 0.118 (control 15), respectively.

Hence, from the SDS PAGE and the mass spectrometric results it was tempting to speculate that the protein ion signals at $\mathrm{m} / \mathrm{z}$ around 13,715 belonged to transthyretin. Consequently, we postulated that transthyretin levels in preeclampsia samples were lower than those in the control samples.

\section{Quantitation of Transthyretin Levels in Serum Samples}

To substantiate the hypothesis that transthyretin levels in sera of patients suffering from preeclampsia were lower than those in control sera, we subjected freshly 
(a)

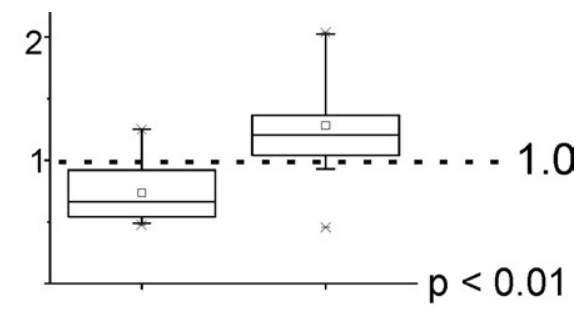

(b)

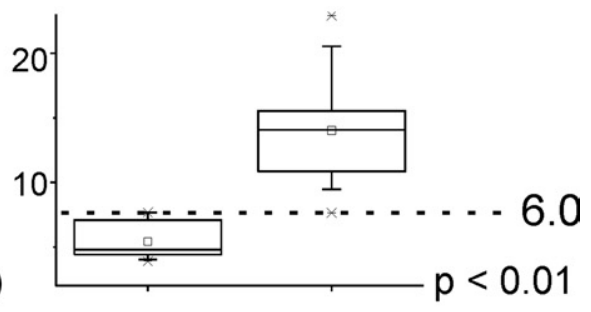

(c)
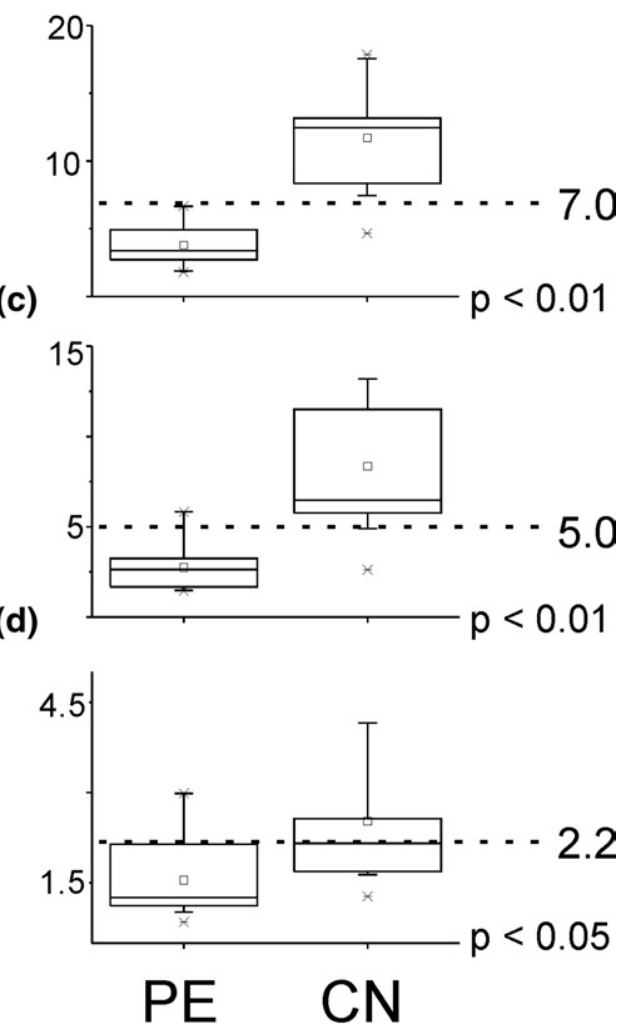

(e) $\quad(n=11) \quad(n=13)$

Figure 5. Box and whisker plots for selected ion intensity differences from measurement five after fractionated precipitation work-up of serum samples. (a) Distribution of signal area values of quotient for $\mathrm{m} / \mathrm{z} 13,715$ and 13,834. (b) Distribution of signal area values of quotient for $m / z 13,891$ and 8886. (c) Distribution of signal area values of quotient for $\mathrm{m} / \mathrm{z} 13,715$ and 8886. (d) Distribution of signal area values of quotient for $\mathrm{m} / \mathrm{z} 13,715$ and 9103. (e) Distribution of signal area values of quotient for $\mathrm{m} / \mathrm{z}$ 13,834 and 9390. The boxes represent the 25th-75th percentiles. The horizontal lines within the boxes represent the median, the small squares indicate the mean. The whiskers specify the 5th and 95th percentiles, and the crosses indicate the 1st and 99th percentiles. Dashed lines mark selected cut-off values. PE: preeclampsia; $\mathrm{CN}$ : control. $P$ values are given.

thawed serum samples to nephelometric analyses. The results from this assay showed that the mean concentration of transthyretin in the preeclampsia group was lower $(0.16 \mathrm{mg} / \mathrm{mL}$; range: 0.13 to 0.20 ; SD: $0.03 ; n=11)$ than that in the control group $(0.19 \mathrm{mg} / \mathrm{mL}$; range: 0.14 to $0.22 ; \mathrm{SD}: 0.02 ; n=13$ ). It should be noted that the Student's $t$-test for two populations showed statistical significance in the difference between the two groups $(P=0.03)$. The on-average lower transthyretin concentration in the preeclampsia group stands in agreement with the results reported above.

\section{Statistical Power Analysis}

Having obtained the data of measurement 1 (MS1), we calculated the minimal required sample size needed for further analyses. By using the rule sets as described above, we calculated a required sample size of $n \leq 10$ patients for each group. This result was achieved also with measurement series MS5 independently with only one exception. Here, ratio " 5 " suggested a sample size of $n=18$, mirroring the poorer differentiation potential as already expected due to the less clear-cut line of separation (see above). However, as in each measurement series a total number of five independent ratios were determined in parallel, the exceptionally higher sample size prediction by one ratio determination was overruled by the accompanying four other ratio considerations. They suggested a smaller sample size $(n \leq 10)$. In summary, we considered the number of patients included in the here described study (11 individuals in the PE group and 13 individuals in the control group) as being sufficient for supporting the statements that resulted from the investigations described here.

\section{Discussion}

During the last decade, preeclampsia has attracted increasing interest among researchers, predominantly because of two main reasons. First, as an acute disorder, preeclampsia is a major cause of maternal and neonatal morbidity and mortality [41], and early identification of the risk of developing the condition would provide a better surveillance during pregnancy and, therefore, improve outcome. Second, as a chronic risk factor, it has become apparent that developing preeclampsia has implications also in later life, i.e., women with preeclampsia during pregnancy are at increased risk of

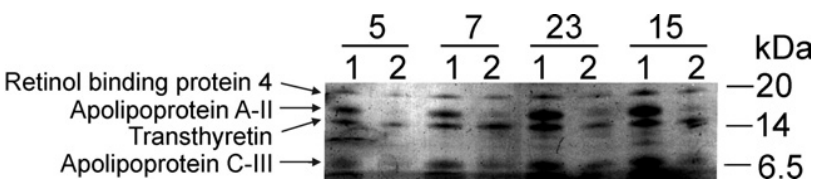

Figure 6. SDS-PAGE analysis ( $12 \% \mathrm{~T}$, mass range: $6-20 \mathrm{kDa})$ of serum proteins before and after fractionated precipitation (fractions II) from preeclampsia and control samples. Protein bands (Coomassie blue staining) from samples of patients with preeclampsia (patients 5 and 7) and from control individuals (15 and 23) before (lanes 1) and after fractionated precipitation (lanes 2) are shown. Mass spectrometrically identified proteins in the bands are indicated at the left. The locations of marker proteins with known apparent masses are given at the right. 
hypertension and cardiovascular diseases throughout their life [42]. Still, the prediction of women at increased risk for developing preeclampsia remains problematic. But only with the help of a reliable predicting marker-or a predicting signature that consists of several markers-it would become meaningful to recruit pregnant women into trials of potential therapeutic agents or treatment with already established early interventions, such as aspirin. The latter has been shown to reduce the recurrence risk of preeclampsia and perinatal death [43].

Few efforts have been made to adopt proteomic methods into the research of pregnancy-related hypertensive disorders. Mass spectrometry was primarily applied to identify proteins of interest after separation of serum and/or plasma proteins by 2D gel electrophoresis. Using such an approach serum clusterin concentrations were found to be significantly increased in preeclampsia [44]. Clusterin is a $70 \mathrm{kDa}$ protein associated with high-density lipoproteins (HDL) in human plasma. It also acts as a control mechanism of the complement cascade as it is present in the $S$ proteincontaining soluble variant of the C5b-9 complex $[45,46]$. Likewise, 36 proteins were identified by liquid chromatography tandem mass spectrometry (LC-MS/MS) upon 2-D fluorescence difference gel electrophoresis (DIGE) during the analysis of protein abundance differences in plasma samples from women with preeclampsia at $20 \mathrm{wk}$ of gestation and preceding the onset of symptoms [47]. Interestingly, 18 of these proteins are associated with HDL particles [48]. The authors suggested these so-called "cargo proteins" to modify the anti-inflammatory properties of HDL and, thus, might be linked to the relationship between preeclampsia and later coronary artery disease. Interestingly, a recent proteome study of plasma proteins of a "late-onset subgroup" of preeclampsia revealed that transthyretin levels, besides other factors, were elevated compared with those from healthy pregnant controls [49].

In the study described here, we observed a group of protein ion signals that can be regarded as a signature for preeclampsia with the most prominent group of ion signals around $m / z$ 13,715. SDS PAGE analysis and peptide mass fingerprinting suggested that the mentioned ion signals belonged to transthyretin. Nephelometric analyses showed consistently lower transthyretin concentrations in samples from preeclampsia patients with respect to the control group. It should be noted that the transthyretin concentrations of all samples were below the reference value for serum, which is expected to be the case during pregnancy due to plasma volume expansion [50]. To the best of our knowledge, this is the first report of a decrease in transthyretin concentration in serum of the "subgroup of severe early-onset preeclampsia" before 34 gestational week with respect to transthyretin levels of individuals with uneventful pregnancies.
Transthyretin is a typical so-called "negative acute phase protein." After trauma, surgery, inflammation, or malnutrition, transthyretin transcription is downregulated in the liver and protein levels in the blood are markedly decreased [51]. Transthyretin acts as a transport molecule for thyroid hormones. Thus, it might ensure the uniform delivery of thyroid hormones throughout all tissues of an organism. Furthermore, it binds the retinol-binding protein, possibly to prevent loss of retinol through glomerular filtration in the kidneys [52]. Most interestingly, transthyretin is not only synthesized by the liver but is also secreted by placental trophoblasts where it binds extracellular T4, which in turn result in an increased internalization of the transthyretin-T4 complex. It has been suggested that transthyretin plays an important role in the transfer of maternal thyroid hormone to the fetal circulation, which could have important implications for fetal development [53].

In our experiments, it turned out that just one marker protein ion signal was not sufficient to differentiate an individual preeclampsia sample from a control sample. By contrast, so-called "multifactorial signatures" are believed to be adequate for distinguishing two polygenic phenotypes to be differentiated [54-58]. Although we did not identify the underlying proteins of the other ion signals in the vicinity of the ion signal at $m / z 13,715$ $(\mathrm{m} / \mathrm{z} 13,891$ and 13,834), it seemed likely that these originated from covalent transthyretin modifications [59]. Likewise, the nature of the many other protein ion signals in our mass spectra has not yet been determined. Our SDS PAGE analysis results indicated that apolipoproteins should perhaps be of interest in this context, putting HDL components again into the focus of research, consistent with above discussed reports [48].

In a comparable screening approach, we recently reported on the development of a proteomic signature applying a mass spectrometry-based method for the HELLP syndrome, where we subjected plasma proteins to MALDI-TOF mass spectrometry. Using an instrument equipped with a cryodetector, we demonstrated that this method enabled the simultaneous recording of significant differences in protein ion intensities between the control group and HELLP patients without sample fractionation, even for larger protein ions above $40 \mathrm{kDa}$ [17]. Further analysis identified serum amyloid A1 (SAA1) to show the most striking differences in abundance from all constituents of the signature. SAA consists of a family of proteins which is functionally up-regulated, presumably due to liver involvement during the HELLP syndrome [3]. Again, this one factor was not considered enough to sort the samples to either belong to the disease group or to the control group, but the signature as a whole yielded satisfactory results.

Altogether, our findings support the theory of preeclampsia being a heterogeneous disorder [21, 22, 60] that might be sub-classified according to different protein concentrations in maternal blood. As is the case for marker proteins, the success of a "multifactorial signa- 
ture" in general is depending on (1) the roles that some of the proteins from the defined signature play in pathogenesis and, perhaps, equally important, (2) the "ease" with which such signatures can be screened in large(r) cohorts of patients. The "preeclampsia signature" described by us relies on differential protein expression in a limited number of patients and, therefore, can be regarded to be in just a preliminary state. It is of note that the clarity of differentiation between preeclampsia and control samples has improved with fractionating serum proteins before performing mass spectrometric analyses. This leaves room for differentiating future samples with more heterogeneities as they are expected with further patient samples.

Also of importance for the analysis of clinical material is to maintain minimal sample manipulation before analysis. Our described procedure fulfills this prerequisite as demonstrated here in an advanced clinical research environment. Although present mass spectrometry-based methods are not yet ready for immediate clinical use as routine diagnostic tools but require close collaboration of clinicians with researchers, it can be envisaged that simple, fast, robust, portable, and cost-effective clinical diagnosis systems could become available soon, which are compatible with usage in the case room. Following this direction, further studies have been initiated by us with the goal to classify subtypes of preeclampsia for a better understanding of the disease. Ultimately, we intend to evaluate the clinical usefulness of the here developed MALDI-TOF MS-based screening approach in a larger multicentric study, and compare efficacy of this method with those of already discussed serum biomarkers.

\section{Acknowledgments}

The authors acknowledge support for this work by grants from the University of Rostock and the University of Aachen. The authors express their thanks to Dr. C. Koy for valuable methodological help and to Mr. M. Hecker for project relevant bioinformatics information. Mrs. M. Sieb is acknowledged for excellent technical assistance. The authors thank Dr. J. Cheung for her valuable comments and for critically reading the manuscript.

\section{Appendix A Supplementary Material}

Supplementary material associated with this article may be found in the online version at doi:10.1016/ j.jasms.2009.12.013.

\section{References}

1. Roberts, J.; Cooper, D. Pathogenesis and Genetics of Preeclampsia. Lancet 2001, 357, 53-56.

2. Lyall, F.; Greer, I. The Vascular Endothelium in Normal Pregnancy and Preeclampsia. Rev. Reprod. 1996, 1, 107-116.

3. Heitner, J. C.; Koy, C.; Reimer, T.; Kreutzer, M.; Gerber, B.; Glocker, M. O. Differentiation of HELLP Patients from Healthy Pregnant Women by Proteome Analysis. J. Chromatogr. B Analyt. Technol. Biomed. Life. Sci. 2006, 840, 10-19.

4. Kadyrov, M.; Kingdom, J. C. P.; Huppertz, B. Divergent Trophoblast Invasion and Apoptosis in Placental Bed Spiral Arteries from Pregnancies
Complicated by Maternal Anemia and Early-Onset Preeclampsia/ Intrauterine Growth Restriction. Am. J. Obstet. Gynecol. 2006, 194, 557-563.

5. Reister, F.; Frank, H. G.; Kingdom, J. C. P.; Heyl, W.; Kaufmann, P.; Rath, W.; Huppertz, B. Macrophage-Induced Apoptosis Limits Endovascular Trophoblast Invasion in the Uterine Wall of Preeclamptic Women. Lab. Invest. 2001, 81, 1143-1152.

6. Holzgreve, W.; Ghezzi, F.; Di Naro, E.; Gänshirt, D.; Maymon, E.; Hahn, S. Disturbed Feto-Maternal Cell Traffic in Preeclampsia. Obstet. Gynaecol. 1998, 91, 669-672.

7. Lo, D. Y. M.; Leung, T. N.; Tein, M. S. C.; Sargent, I. L.; Zhang, J.; Lau, T. K.; Haines, C. J.; Redman, C. W. G. Quantitative Abnormalities of Fetal DNA in Maternal Serum in Preeclampsia. Clin. Chem. 1999, 45, 184-188.

8. Levine, R. J.; Lam, C.; Qian, C.; Yu, K. F.; Maynard, S. E.; Sachs, B. P.; Sibai, B. M.; Epstein, F. H.; Romero, R.; Thadhani, R.; Karumanchi, S. A. Soluble Endoglin and Other Circulating Antiangiogenic Factors in Preeclampsia. N. Engl. J. Med. 2006, 355, 992-1005.

9. Levine, R. J.; Maynard, S. E.; Qian, C.; Lim, K. H.; England, L. J.; Yu, K. F.; Schistermann, E. F.; Thadhani, R.; Sachs, B. P.; Epstein, F. H.; Sibai, B. M.; Sukhatme, V. P.; Karumanchi, S. A. Circulating Angiogenic Factors and the Risk of Preeclampsia. N. Engl. J. Med. 2004, 350, 672-683.

10. Aquilina, J.; Barnet, A.; Thompson, O.; Harrington, K. Second-Trimester Maternal Serum Inhibin A Concentration as an Early Marker for Preeclampsia. Am. J. Obstet. Gynecol. 1999, 181, 131-136.

11. Bersinger, N. A.; Smárason, A. K.; Muttukrishna, S.; Groome, N. P. Women with Preeclampsia Have Increased Serum Levels of PregnancyAssociated Plasma Protein A (PAPP-A), Inhibin A, Activin A, and Soluble E-Selectin. Hypertens. Pregnancy 2003, 22, 45-55.

12. Cetin, I.; Cozzi, V.; Pasqualini, F.; Nebuloni, M.; Garlanda, C.; Vago, L.; Pardi, G.; Mantovani, A. Elevated Maternal Levels of the Long Pentraxin 3 (PTX3) in Preeclampsia and Intrauterine Growth Restriction. Am. J. Obstet. Gynecol. 2006, 194, 1347-1353.

13. Huppertz, B.; Sammar, M.; Chefetz, I.; Neumaier-Wagner, P.; Bartz, C.; Meiri, H. Longitudinal Determination of Serum Placental Protein 13 During Development of Preeclampsia. Fetal Diagn. Ther. 2008, 24, $230-236$.

14. Muttukrishna, S.; Knight, P. G.; Groome, N. P.; Redman, C. W. G.; Ledger, W. L. Activin A and Inhibin A as Possible Endocrine Markers for Preeclampsia. Lancet 1997, 349, 1285-1288.

15. Nicolaides, K. H.; Bindra, R.; Turan, O. M.; Chefetz, I.; Sammar, M.; Meiri, H.; Tal, J.; Cuckle, H. S. A Novel Approach to First-Trimester Screening for Early Preeclampsia Combining Serum PP-13 and Doppler Ultrasound. Ultrasound Obstet. Gynecol. 2006, 27, 13-17.

16. Conde-Agudelo, A.; Villar, J.; Lindheimer, M. World Health Organization Systematic Review of Screening Tests for Preeclampsia. Obstet. Gynaecol. 2004, 104, 1367-1391.

17. Koy, C.; Heitner, J. C.; Woisch, R.; Kreutzer, M.; Serrano-Fernandez, P.; Gohlke, R.; Reimer, T.; Glocker, M. O. Cryodetector Mass Spectrometry Profiling of Plasma Samples for HELLP Diagnosis: An Exploratory Study. Proteomics 2005, 5, 3079-3087.

18. Palmblad, M.; Tiss, A.; Cramer, R. Mass Spectrometry in Clinical Proteomics-from the Present to the Future. Proteomics Clin. Appl. 2009, $3,6-17$.

19. Report of the National High Blood Pressure Education Program Working Group on High Blood Pressure in Pregnancy. Am. J. Obstet. Gynecol. 2000, 183, S1-S22.

20. Brown, M. A.; Lindheimer, M. D.; de Swiet, M.; Van Assche, A. Moutquin, J. M. The Classification and Diagnosis of the Hypertensive Disorders of Pregnancy: Statement from the International Society for the Study of Hypertension in Pregnancy (ISSHP). Hypertens. Pregnancy 2001, 20,9-14.

21. Villar, J.; Carroli, G.; Wojdyla, D.; Abalos, E.; Giordano, D.; Ba'aqeel, H. Farnot, U.; Bergsjo, P.; Bakketeig, L.; Lumbiganon, P.; Campodónico, L.; Al-Mazrou, Y.; Lindheimer, M.; Kramer, M. Preeclampsia, Gestational Hypertension and Intrauterine Growth Restriction, Related or Independent Conditions? Am. J. Obstet. Gynecol. 2006, 194, 921-931.

22. von Dadelszen, P.; Magee, L. A.; Roberts, J. M. Subclassification of Preeclampsia. Hypertens. Pregnancy. 2003, 22, 143-148.

23. Voigt, M.; Schneider, K. T.; Jährig, K. Analysis of a 1992 Birth Sample in Germany. 1: New Percentile Values of the Body Weight of Newborn Infants. Geburtshilfe Frauenheilkd 1996, 56, 550-558.

24. Cohn, E. J.; Oncley, J. L.; Strong, L. E.; Hughes, J.; Walter L.; Armstrong, J.; S. Howard Chemical, Clinical, and Immunological Studies on the Products of Human Plasma Fractionation. I. The Characterization of the Protein Fractionations of Human Plasma. J. Clin. Invest. 1944, 23, 417-432.

25. Mikkat, S.; Koy, C.; Ulbrich, M.; Ringel, B.; Glocker, M. O. Mass Spectrometric Protein Structure Characterization Reveals Cause of Migration Differences of Haptoglobin $\alpha$ Chains in Two-Dimensional Gel Electrophoresis. Proteomics 2004, 4, 3921-3932.

26. Wilcoxon, F. Individual Comparisons by Ranking Methods. Biometrics 1945, 1, 80-83.

27. Kruskal, W. H.; Wallis, A. W. Use of Ranks in One-Criterion Variance Analysis. J. Am. Stat. Assoc. 1952, 47, 583-621.

28. Chambers, J. M.; Freeny, A. E.; Heiberger, R. M. Analysis of Variance; Designed Experiments. In Statistical Models in S, Chambers, J. M.; Hastie, T. J.; Eds.; Wadsworth and Brooks/Cole: Pacific Grove, CA, 1992; p. 145.

29. Walpole R. E.; Myers R. Probability and Statistics for Engineers and Scientists, 5th ed. Macmillan: New York, 1993. 
30. Stephens, M. A. EDF Statistics for Goodness of Fit and Some Comparisons. J. Am. Stat. Assoc. 1974, 69, 730-737.

31. Tukey J. W. Exploratory Data Analysis, 1st ed.; Addison Wesley: Munich, 1977.

32. Kienbaum, M.; Koy, C.; Montgomery, H. V.; Drynda, S.; Lorenz, P.; Illges, H.; Tanaka, K.; Kekow, J.; Guthke, R.; Thiesen, H. J.; Glocker, M. O. Mass Spectrometric Characterization of Apheresis Samples from Rheumatoid Arthritis Patients for the Improvement of Immunoadsorption Therapy-A Pilot Study. Proteom. Clin. Appl. 2009, 3, 797-809.

33. Laemmli, U. K. Cleavage of Structural Proteins During the Assembly of the Head of Bacteriophage T4. Nature 1970, 227, 680-685.

34. Bantscheff, M.; Ringel, B.; Madi, A.; Schnabel, R.; Glocker, M. O.; Thiesen, H. J. Differential Proteome Analysis and Mass Spectrometric Characterization of Germ Line Development-Related Proteins of Caenorhabditis elegans. Proteomics 2004, 4, 2283-2295.

35. Candiano, G.; Bruschi, M.; Musante, L.; Santucci, L.; Ghiggeri, G. M.; Carnemolla, B.; Orecchia, P.; Zardi, L.; Righetti, P. G. Blue Silver: A Very Sensitive Colloidal Coomassie G-250 Staining for Proteome Analysis. Electrophoresis 2004, 25, 1327-1333.

36. Koy, C.; Mikkat, S.; Raptakis, E.; Sutton, C.; Resch, M.; Tanaka, K.; Glocker, M. O. Matrix-Assisted Laser Desorption/Ionization-Quadrupole Ion TrapTime of Flight Mass Spectrometry Sequencing Resolves Structures of Unidentified Peptides Obtained by In-Gel Tryptic Digestion of Haptoglobin Derivatives from Human Plasma Proteomes. Proteomics 2003, 3, 851858 .

37. Koy, C.; Resch, M.; Tanaka, K.; Glocker, M. O. Primary Structure Details of Haptoglobin a Chain Proteins from Human Plasma Samples are Resolved by QIT TOF MS ${ }^{n}$ sequencing. Eur. J. Mass Spectrom. 2004, 10, 393-399.

38. Schoonjans, F.; Zalata, A.; Depuydt, C. E.; Comhaire, F. H. MedCalc: A New Computer Program for Medical Statistics. Comput. Methods Programs Biomed. 1995, 48, 257-262.

39. Obuchowski, N. A.; Zhou, X.-H. Prospective Studies of Diagnostic Test Accuracy When Disease Prevalence is Low. Biostatistics 2002, 3, 477492.

40. Oettle, C.; Hall, D.; Roux, A.; Grové, D. Early Onset Severe Preeclampsia: Expectant Management at a Secondary Hospital in Close Association with a Tertiary Institution. BJOG 2005, 112, 84-88.

41. Rath, W.; Faridi, A.; Dudenhausen, J. W. HELLP Syndrome. J. Perinat. Med. 2000, 28, 249-260.

42. Bellamy, L.; Casas, J. P.; Hingorani, A. D.; Williams, D. J. Preeclampsia and Risk of Cardiovascular Disease and Cancer in Later Life: Systematic Review and Meta-Analysis. Br. Med. J. 2007, 335, 974-985.

43. Coomarasamy, A.; Honest, H.; Papaioannou, S.; Gee, H.; Khan, K. S. Aspirin for Prevention of Preeclampsia in Women With Historical Risk Factors: A Systematic Review. Obstet. Gynaecol. 2003, 101, 1319-1332.

44. Watanabe, H.; Hamada, H.; Yamada, N.; Sohda, S.; YamakawaKobayashi, K.; Yoshikawa, H.; Arinami, T. Proteome Analysis Reveals Elevated Serum Levels of Clusterin in Patients with Preeclampsia. Proteomics 2004, 4, 537-543.

45. de Silva, H. V.; Stuart, W. D.; Park, Y. B.; Mao, S. J.; Gil, C. M.; Wetterau, J. R.; Busch, S. J.; Harmony, J. A. Purification and Characterization of Apolipoprotein. J. Biol. Chem. 1990, 265, 14292-14297.

46. Murphy, B. F.; Kirszbaum, L.; Walker, I. D.; d'Apice, A. J. SP-40,40, a Newly Identified Normal Human Serum Protein Found in the SC5b-9 Complex of
Complement and in the Immune Deposits in Glomerulonephritis. J. Clin. Invest. 1988, 81, 1858-1864.

47. Blumenstein, M.; McMaster, M. T.; Black, M. A.; Wu, S.; Prakash, R.; Cooney, J.; McCowan, L. M.; Cooper, G. J.; North, R. A. A Proteomic Approach Identifies Early Pregnancy Biomarkers for Preeclampsia: Novel Linkages Between a Predisposition to Preeclampsia and Cardiovascular Disease. Proteomics 2009, 9, 2929-2945.

48. Vaisar, T.; Pennathur, S.; Green, P. S.; Gharib, S. A.; Hoofnagle, A. N. Cheung, M. C.; Byun, J.; Vuletic, S.; Kassim, S.; Singh, P.; Chea, H.; Knopp, R.; Brunzell, J.; Geary, R.; Chait, A.; Zhao, X. Q.; Elkon, K.; Marcovina, S.; Ridker, P.; Oram, J.; Heinecke, J. W. Shotgun Proteomics Implicates Protease Inhibition and Complement Activation in the Anti-Inflammatory Properties of HDL. J. Clin. Invest. 2007, 117, 746-756.

49. Atkinson, K. R.; Blumenstein, M.; Black, M. A.; Wu, S. H.; Kasabov, N.; Taylor, R. S.; Cooper, G. J.; North, R. A.; SCOPE Consortium. An Altered Pattern of Circulating Apolipoprotein E3 Isoforms is Implicated in Preeclampsia. J. Lipid Res. 2009, 50,71-80.

50. Sapin, V.; Alexandre, M. C.; Chaib, S.; Bournazeau, J. A.; Sauvant, P.; Borel, P.; Jacquetin, B.; Grolier, P.; Lémery, D.; Dastugue, B.; AzaisBraesco, V. Effect of Vitamin A Status at the End of Term Pregnancy on the Saturation of Retinol Binding Protein with Retinol. Am. J. Clin. Nutr. 2000, 71, 537-543.

51. Dickson, P. W.; Howlett, G. J.; Schreiber, G. Metabolism of Prealbumin in Rats and Changes Induced by Acute Inflammation. Eur. J. Biochem. 1982, 129, 289-293.

52. Raz, A.; Goodman, D. S. The Interaction of Thyroxine with Human Plasma Prealbumin and with the Prealbumin-Retinol-Binding Protein Complex. J. Biol. Chem. 1969, 244, 3230-3237.

53. Landers, K. A.; McKinnon, B. D.; Li, H.; Subramaniam, V. N.; Mortimer R. H.; Richard, K. Carrier-Mediated Thyroid Hormone Transport into Placenta by Placental Transthyretin. J. Clin. Endocrinol. Metab. 2009, 94, 2610-2616.

54. Alldridge, L.; Metodieva, G.; Greenwood, C.; Al-Janabi, K.; Thwaites, L.; Sauven, P.; Metodiev, M. Proteome Profiling of Breast Tumors by Gel Electrophoresis and Nanoscale Electrospray Ionization Mass Spectrometry. J. Proteome Res. 2008, 7, 1458-1469.

55. Röwer, C.; Vissers, J. P. C.; Koy, C.; Kipping, M.; Hecker, M.; Reimer, T. Gerber, B.; Thiesen, H. J.; Glocker, M. O. A Proteome Signature for Breast Carcinoma Derived from Label-Free Nanoscale LC-MS Protein Expression Profiling of Tumor and Glandular Tissue-A Methodology Study. Anal. Bioanal. Chem. 2009, in press.

56. Seike, M. Kondo, T.; Fujii, K.: Yamada, T.; Gemma, A.; Kudoh, S Hirohashi, S. Proteomic Signature of Human Cancer Cells. Proteomics 2004, 4, 2776-2788.

57. Wang, M.; You, J.; Bemis, K. G.; Tegeler, T. J.; Brown, D. P. G. Label-Free Mass Spectrometry-Based Protein Quantification Technologies in Proteomic Analysis. Brief Funct. Genom. Proteom. 2008, 7, 329-339.

58. Yamada, M.; Fujii, K.; Koyama, K.; Hirohashi, S.; Kondo, T. The Proteomic Profile of Pancreatic Cancer Cell Lines Corresponding to Carcinogenesis and Metastasis. J. Proteome Bioinform. 2009, 2, 001-018.

59. Shimizu, A.; Nakanishi, T.; Miyazaki, A. Detection and Characterization of Variant and Modified Structures of Proteins in Blood and Tissues by Mass Spectrometry. Mass Spectrom. Rev. 2006, 25, 686-712.

60. Huppertz, B. Placental Origins of Preeclampsia: Challenging the Current Hypothesis. Hypertension 2008, 51, 970-975. 